\title{
POSSIBILITIES OF EU FUNDS IN SOCIAL DIALOGUE DEVELOPMENT: CASE STUDY OF CROATIA
}

\author{
Marko Šostar, Antun Marinac, \& Berislav Andrlić \\ Polytechnic of Požega (Republic of Croatia)
}

\begin{abstract}
Social dialogue is the cornerstone of European social policy and helps create decent working conditions for all workers and workers, improving work legislation and developing social partnership as a tool to achieve all common goals such as job creation, improved living standards and economic growth. Bipartite social dialogue is a dialogue directly between social partners (appropriate level of associations of employers and trade unions) as well as negotiations held within its framework. It needs to be emphasized that in Croatia, as a new democracy with relatively short tradition of social dialogue, social dialogue is not only collective bargaining but it also comprises dialogue and negotiations. Although Croatian legislation guarantees protection of workers' rights, in practice, however, many of them are violated on a daily basis. The research is also focused on the analysis of the EU funds available to finance projects in the area of social dialogue development. The research was conducted in the form of a survey to analyze employee satisfaction with the public sector on their rights and work obligations. The aim of the research is to improve the quality of social dialogue through the development and strengthening of administrative and professional capacities of social partners at international, national, regional, local and sectoral level.
\end{abstract}

Keywords: EU funds, social dialogue, worker's rights, social partners.

\section{Introduction}

The idea of social partnership gained its clear, recognizable institutional profile at the end of the 19th century, when in Germany, legislative reforms were defined to provide workers with certain risks, such as age, illness, accidents at work. Partnership is historically the most obviously related to the development of a social-market economy and the principles of subsidiarity. Such an understanding of the social partnership is also built on the foundations of the European Union. At European level social dialogue is an integral part of the acquis communitarian on the basis of Articles 138 and 139 of the Treaty establishing the European Community. In the later period, it is important to note that Jaques Delors, European Commission President, in 1985 defined the role of social partners at European level, which was recognized and successfully strengthened by the Maastricht and Amsterdam Agreements. From the experience of the European Union, it can be concluded that the idea of social partnership has undergone great development, especially in the nineties of the last century, since social partners have since gained wide scope for participation in the consultation process, and social and civil dialogue have become the foundation of good governance in the European Union. The term "partnership" emphasizes one important component of the relationship: understanding and appreciation.

Strong social partners and a good social dialogue can play an important role in the economic and social development process in a country, as evidenced by examples from various countries. A good social dialogue results in fewer strikes, improved protection of employees, greater employee satisfaction, increased employment and higher labor productivity. In many Western democracies, social dialogue has made an important contribution to growth and continued prosperity. However, it is important that employers, unions and government are constantly aware of their mutual dependency on the further development of society. (Nieuwsma \& Boorsm, 2017)

There are three principles that social dialogue contributes to the achievement of social and economic development objectives: inclusiveness, democratic ownership and accountability. Social dialogue promotes inclusiveness, with representative and independent workers' and employers' organisations, alongside governments, seeking solutions to issues of common concern. As representative organisations, the social partners bring together the points of view of a multitude of employees and employers. In the case of the trade unions, this is further reinforced by their democratic structures and elected leadership. In developing countries, there are also indications that informal workers and their 
organisations are increasingly being represented in social dialogue structures through trade union representation. In academic literature, this is described as providing voice to key stakeholders by offering channels for participation in decision-making processes. Social dialogue has been found to be capable of resolving collective action problems in the area of decent work and beyond. Similarly, social dialogue can set common standards or wage levels in a region or sector, thus to some degree removing these elements from competition and accordingly reducing the likelihood of a downward spiral in labour and environmental conditions. Social dialogue, through its inherent processes of information-sharing, consultation, negotiation and joint decision-making, allows the social partners to share their views on and influence the policies or measures that affect them. These are important ingredients of democracy and can improve the prospect of democratic ownership and the effective implementation of such policies or measures by the public authorities and the social partners. In addition, social dialogue offers a number of opportunities to strengthen transparency and accountability among the various actors involved. (HIVA Research Institute for Work and Society, 2017)

\section{Advantages of EU funds in social dialogue development in Croatia}

The social dialogue is not deeply enrooted within the Croatian society, similar to other former socialist countries. The first steps towards creating institutional and political framework for social dialogue in the country was taken in 1994 with the establishment of the national Economic and Social Council and identifying its competences. Over the next several years, the functioning of the social dialogue was rather limited and reduced to a rather formal and declaratory action. After the parliamentary elections in 2000 the new Government had restored tripartite dialogue at the national level and launched new framework for the development of the social dialogue. Croatia has ratified a number of International Labour Organization (ILO) Conventions and the European Social Charter. Institutional basis for the social dialogue in Croatia is comprised of the Economic and Social Council (ESC) and the Government Office for Social Partnership. The Croatian Economic and Social Council (ESC) is a forum in which key social partners (high representatives of the Government, employers' associations and trade unions) discuss and negotiate important decisions on key economic and social issues. The Economic and Social Council has commissions for the following topics: wage policy and the tax system, employment and social policy, collective bargaining, privatization, education and labour market, legislation, regulation implementation and legal protection, international relations and accession, national budget, pension and health care, and alternative resolution of labour disputes. The ESC can suggest discussing any legislative proposal from the Government before it enters into parliamentary procedure. In majority of cases, such suggestions are accepted. Each social partner has the right to a one vote in ECS and its bodies. Members of ESC can also give a separate opinion but this opinion is not visible when a particular legislative proposal enters into a parliamentary procedure. Similar to other CEE countries, tripartite social dialogue at national level in Croatia is quite developed, unlike bipartite dialogue which is still facing many difficulties. Collective agreements have covered almost all employees in the public sector, as well as in the most of the state-owned companies. Capacities of trade unions are not fully prepared to participate in the sector dialogue and, consequently, sometimes there is a lack of initiative for such dialogue on their part. Furthermore, there is a lack of a tradition of social dialogue in general and unwillingness of private sector to accept trade unions as partners, particularly in collective bargaining. Number of collective agreements in private sector is notably lower than in the public sector. (Samardžija, 2008)

Graphic 1. Benefits from developing social dialogue.

\section{BENEFITS FOR EMPLOYERS}

\section{BENEFITS FOR EMPLOYEES}

\section{BENEFOST FOR GOVERNMENT}

Source: DECP, 2017 
It is crucial to develop social dialogue in the European Union as well as in Croatia. There are many benefits for employers, employees and government. Employers have benefit from social dialogue, because countries with a good social dialogue generally have fewer strikes. The business and investment climate are also better than elsewhere. Another benefit for employers is that industrial peace improves their competitive position and productivity. Working together with the unions also results in employers' organisations having more influence in government policy and in politics. If employers and unions agree on a socio-economic topic, then it is hard for politicians to take a very different stance. Similarly, unions are also able to exercise greater influence on government and parliament thanks to social dialogue. Structural consultations with employers generally result in lower unemployment figures and a smaller income disparity in society. For individual employees, social dialogue often results in a broader range in the employment package and improved employment conditions. In fully-fledged democracies, the government together with parliament has the final say. Nevertheless, the government leaves certain aspects of employ meant relationships and employment conditions to the employers and the unions. The benefit for the government is that this results in greater acceptance of the solution that is eventually proposed. This in turn increases the likelihood of the envisaged results actually being achieved. (Nieuwsma \& Boorsm, 2017)

In the past several years, social dialogue in Croatia has encountered some difficulties, partly due to accelerated legislative activities for the Croatian accession to the European Union, and partly due to the negative impact of the economic and social crisis that led to measures being taken without properly consulting social partners. Furthermore, although the local (county-level) economic and social councils were established, many of them are not functional. For that reason, improving social dialogue, particularly tripartite dialogue structures and practices were defined as project's main long-term goal. There is possibility to develop social dialogue in Croatia through financing innovative projects in the field of social dialogue by EU funds. Funding through the Social Fund entitled "Boosting Social Dialogue" is a good way to do a step forward. The goal of tender is to improve the quality of social dialogue through the development and strengthening of administrative and professional capacities of social partners at international, national, regional, local and sectoral levels. Potential applicants are social partners: trade unions, higher-level union associations, employers 'associations, higher-level employers' associations, local and regional self-government unit and Development Agencies. The projects are also financed in $100 \%$ of the amount by the European Union. Acceptable activities are: project management and administration, strengthening sectoral social dialogue and sectoral social councils, empowering the professional, analytical and advocacy capacities of social partners, analysis, research and monitoring of social dialogue, strengthening the capacities of Croatian social partners through international co-operation, participation in international social partnerships, at EU and global level, and international forms of employee participation, promotion and visibility (European Social Fund, 2017)

\section{Research and results}

A survey was conducted through a survey questionnaire. The respondents were 125 employees of 47 different employers. The survey explored employee satisfaction at the workplace as well as respecting the rights and obligations of employees.

Graphic 2. The level of discrimination at the workplace.

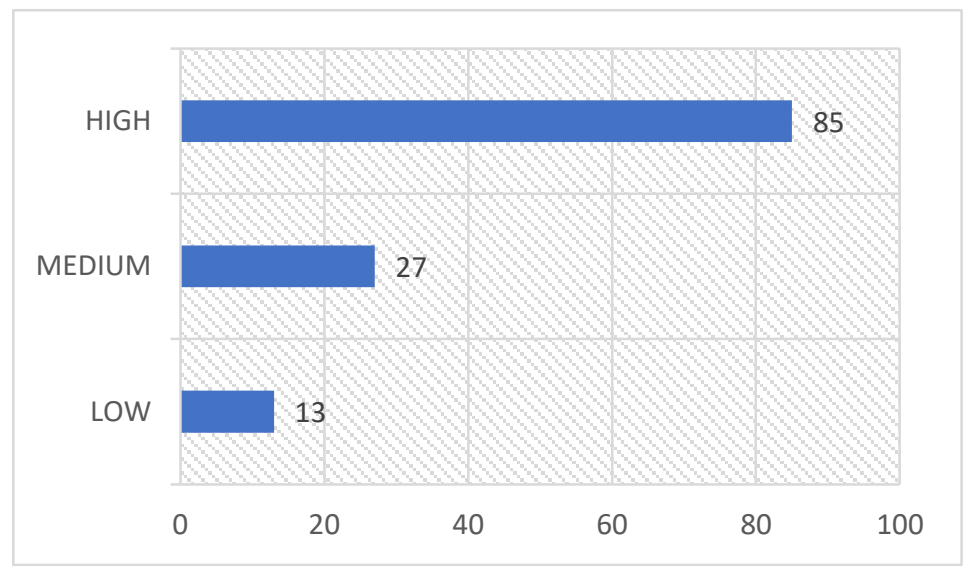

Source: Authors research 
As we can see there is a very high level of discrimination of the workers in Croatia, 85 of responders indicated high level and 27 on medium level of discrimination while only 13 responders think opposite.

Graphic 3. The level of mobbing at working place.

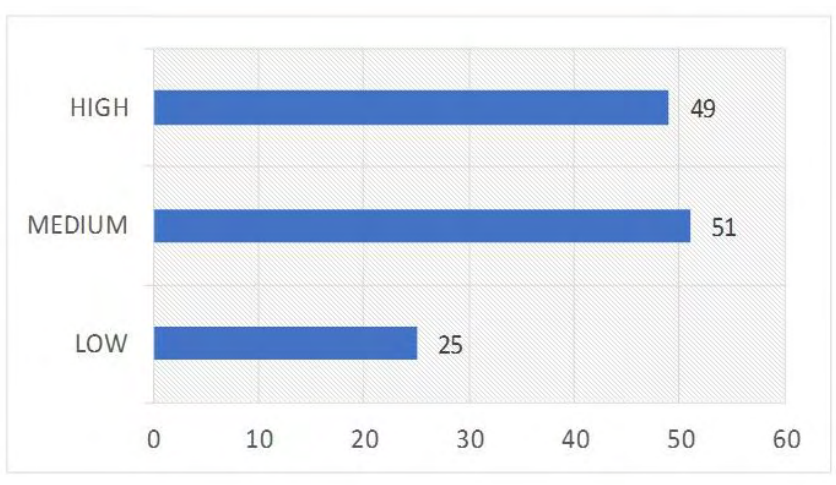

Source: Authors research

As we can see there is a very high level of discrimination of the mobbing in Croatia, 49 of responders indicated high level and 51 on medium level of mobbing while only 25 responders think opposite.

Graphic 4. Overtime without payment.

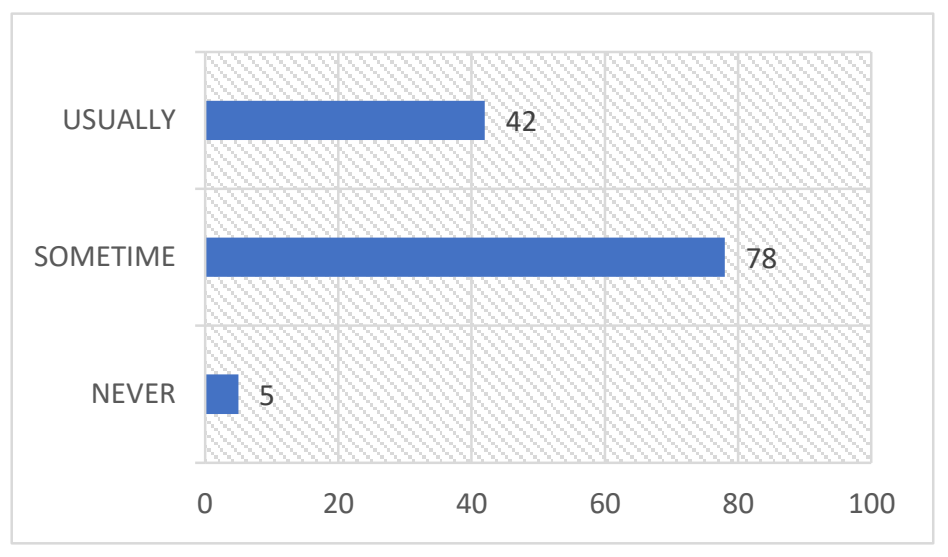

Source: Authors research

As we can see there is a big problem of overtime working hours. Employees usually (42 responders) and sometimes (78 responders) work overtime but not get payed for that.

Graphic 5. Working environment and conditions.

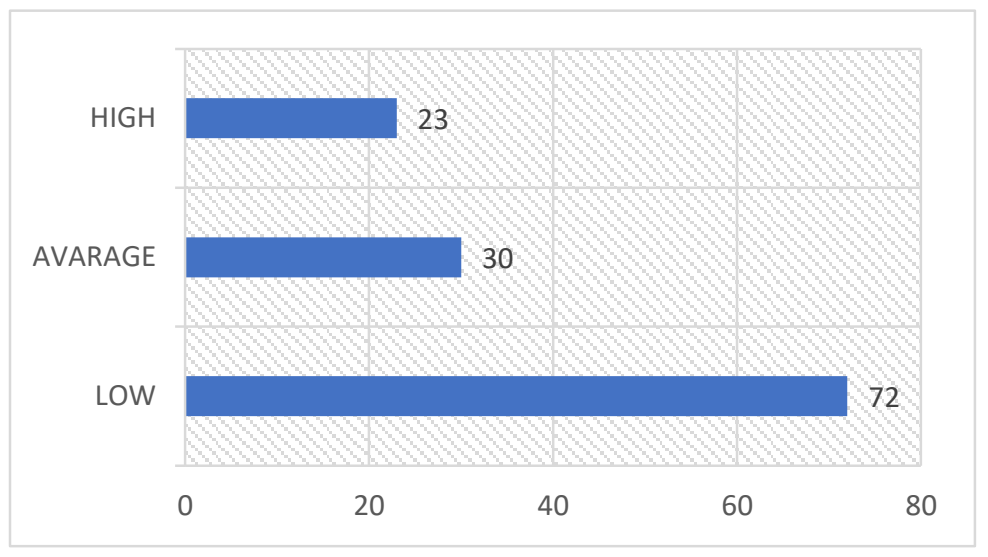

Source: Authors research 
As we can see there is a very low level of working conditions in Croatian firms (72 responders) while only 23 responders are happy with the working conditions.

Graphic 6. The level of stimulation for good work.

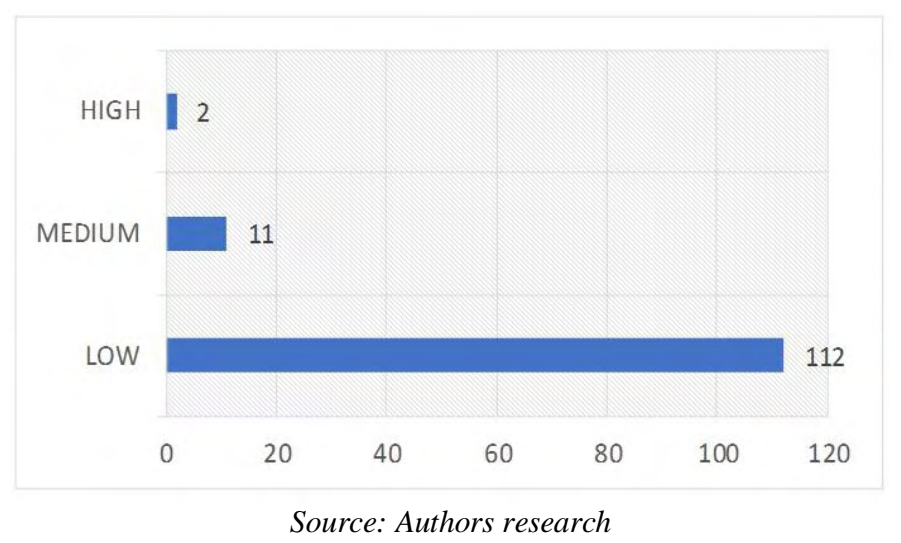

As we can see there is a very low level of stimulation for good work in Croatian firms. From 125 responders almost every single of them (112 responders) didn't get any kind of stimulation for their good work, while only 2 of them have some different experience.

\section{Conclusion}

Social dialogue is the key to the success of every enterprise, but also the country where the company is located. Communication, positive synergy and common co-operation are necessary to be happy with employees on the one hand and employers on the other. The conducted survey showed great dissatisfaction with employees with discrimination at the workplace, daily mobbing, overtime without pay, working environment and working conditions as well as job de-mining. These are the areas in which the country's considerable efforts must be made to preserve the dignity of the workers. It is important to put emphasis on bipartite and tripartite social dialogue. Bipartite dialogue is dialogue between employers' organisations and workers' organisations and it refers to the discussions, consultations, negotiations and joint actions involving the two sides of industry. Tripartite social dialogue involves the governmental institutions as well as the social partners. The economic crisis represents a serious challenge for dialogue between workers' representatives and employers and government representatives. Government reforms have not always been accompanied by effective social dialogue, which has led to increasingly conflicting relations in the industry. Participation of workers' representatives and employers or social partners in government reforms is important because solutions achieved through social dialogue tend to wider acceptance in society and it is easier to implement decisions made in practice and thus less conflict. Contracts involving social partners ensure long-term sustainability of economic and social reforms. Well-structured social dialogue can effectively contribute to Europe's economic sustainability. Despite the poor results of research and employee dissatisfaction, a better shift is visible. In particular, this shift is visible in terms of financing projects in the area of social dialogue through funds from EU funds. Such projects are the only ones that can encourage all stakeholders of social dialogue to cooperate.

\section{References}

ESF (2017): Social dialogue Straightened, Bruxells: European Social Fund. Retrieved: 10.02.2019., from: http://www.esf.hr/natjecaji/dobro-upravljanje/jacanje-socijalnog-dijaloga-faza-iii/

HIVA Research Institute for Work and Society (2017). Social dialogue as a driver and governance instrument for sustainable development, ILO-ITUC Issue Paper. Retrieved: 15.02.2019., from: https://www.ituc-csi.org/issue-paper-social-dialogue-development

Nieuwsma, S. \& Boorsm, P. (2017). Options for social dialogue. Hague: DECP. Retrieved: 25.02.2019., from: www.decp.nl/download.asp?id=1327

Samardžija, V. (2008). The challenges for Croatia in European social dialogue. Institute for International Relations Croatian International Relations Review. Vol. 14 No. 52/53, 2008., Zagreb, p. 83-94 